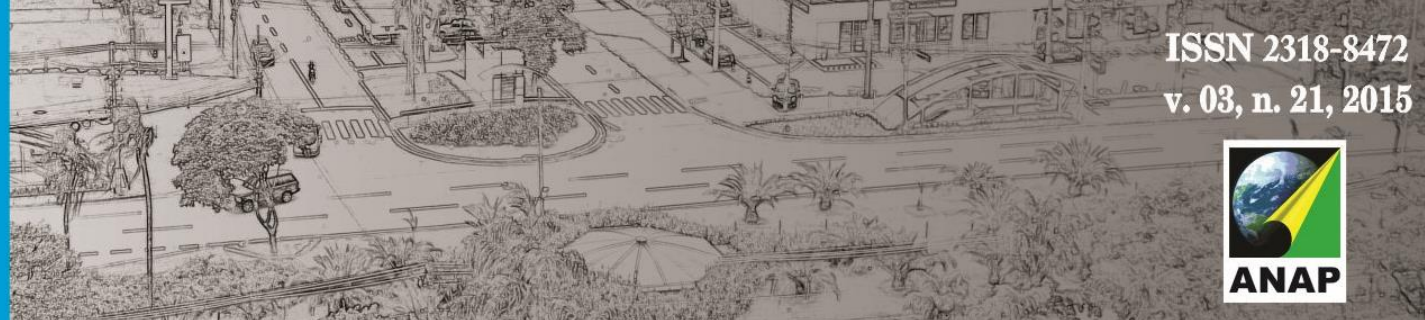

Revista Nacional de

Gerenciamento de Cidades

\title{
AVALIAÇÃO DAS INFRAESTRUTURAS DA PRAÇA SÃO JOSÉ E DA PRAÇA GETÚLIO VARGAS NA CIDADE DE CAMPO MOURÃO - PR, BRASIL
}

Tatiane Monteiro Ré ${ }^{1}$

Marcos Clair Bovo ${ }^{2}$

RESUMO: As praças são importantes espaços públicos para a população citadina, visto que são utilizadas como local de lazer e de convivência. Elas exercem várias funções como a estética, ecológica e simbólica. Tendo em vista a importância das praças para as cidades a presente pesquisa tem como objetivo/intenção caracterizar e analisar a Praça São José e a Praça Getúlio Vargas na cidade de Campo Mourão (PR), destacando os aspectos paisagísticos e as infraestruturas existentes. Também pretende-se propor medidas que auxiliem no planejamento e gerenciamento destes logradouros. A pesquisa inicia-se fazendo uma breve reflexão teórica a respeito da praça enquanto espaço público e na sequência por meio da pesquisa in loco realiza-se o levantamento dos aspectos qualitativos e quantitativos dos equipamentos e estruturas presentes em cada praça, tendo por base metodologia desenvolvida por De Angelis (2000) que utiliza parâmetros fixos para analisar infraestrutura e equipamentos existentes. Os resultados indicam que ambas as praças possuem boa infraestrutura e equipamentos destinado ao uso da população, além de desempenhar a função estética, ecológica e simbólica.

PALAVRAS-CHAVE: Praça. Infraestrutura. Espaço público.

\footnotetext{
${ }^{1}$ Mestranda do Programa de Pós-Graduação Interdisciplinar Sociedade e Desenvolvimento da Universidade Estadual do Paraná - Campus de Campo Mourão. E-mail: tatiane@utfpr.edu.br

${ }^{2}$ Professor Adjunto do Colegiado de Geografia e do Programa de Pós-Graduação Interdisciplinar Sociedade e Desenvolvimento da Universidade Estadual do Paraná - Campus de Campo Mourão. Avenida Comendador Norberto Marcondes, 733, CEP: 87303- 100. Campo Mourão - PR. Email: mcbovo69@gmail.com
} 


\title{
ASSESSMENT OF THE INFRASTRUCTURE OF THE SQUARE SÃO JOSÉ AND SQUARE GETÚLIO VARGAS IN CAMPO MOURÃO CITY -
}

\author{
PR, BRAZIL
}

\begin{abstract}
Public squares are important to townsmen, as they are places used to recreation and acquaintanceship. Further, they exert distinct functions, like aesthetic, ecologic and symbolic. In view of the importance of public squares to the cities, the present research is intended to analyze and characterize two squares of Campo Mourão, named São José and Getúlio Vargas, highlighting landscaped aspects and existent infrastructure. We also intend to propose actions to assist in the planning and management of these public sites. Our first step is to make a brief theoretical reflection regarding to squares as public spaces, and hereafter to perform a survey on qualitative and quantitative aspects of equipments and structures located in each square by means of in loco research. The qualitative and quantitative surveys are carried out based on the methodology proposed by De Angelis (2000), that uses fixed parameters to analyze equipments and structures. Obtained results indicate that studied squares have good equipments and infrastructure destined to population use. Moreover, the squares perform aesthetic, ecologic and symbolic functions as well.
\end{abstract}

KEYWORDS: Square. Infrastructure. Public place.

\section{EVALUACIÓN DE LA INFRAESTRUCTURA DE LA PLAZA SÃO JOSÉ Y PLAZA GETÚLIO VARGAS EN CAMPO MOURÃO CITY - PR, BRASIL}

\begin{abstract}
RESUMEN: Las plazas son espacios públicos importantes para la población de la ciudad, ya que son utilizadas como lugar de ocio y convivencia. Ejercen diversas funciones tales como la estética, la ecológica y la simbólica. Dada la importancia de las plazas de las ciudades, esta investigación tiene como objetivo/ intención caracterizar y analizar la Plaza de San José y la plaza Getúlio Vargas en la ciudad de Campo Mourão - PR, destacando las características del paisaje y infraestructura existente. Además, se pretende proponer medidas que ayuden a la planificación y gestión de estos espacios públicos. La investigación se inicia con una breve reflexión teórica sobre la plaza como espacio público y después, a través de investigación in loco, fue realizado el levantamiento de aspectos cualitativos y cuantitativos de los equipos y estructuras presentes en cada plaza, basado em la metodología desarrollada por De Angelis (2000), que utiliza parámetros fijos para analizar cada infraestructura y equipos existentes. Los resultados indican que las dos plazas tienen buena infraestrura y equipos destinados al uso de la población, además de desepeñar la función estética, ecológica y simbólica.
\end{abstract}

PALABRAS CLAVE: Plaza. Infraestructura. Espacio público. 


\section{Revista Nacional de}

Gerenciamento de Cidades

\section{INTRODUÇÃO}

Desde a década de 1970, as cidades brasileiras têm passado por vários problemas. Dentre eles, destacamos o déficit habitacional, a poluição do ar e das águas, a carência de infraestrutura básica, a falta de locomoção, a ausência de áreas verdes e, consequentemente, a diminuição da qualidade de vida dos citadinos. Assim, crescem com as cidades os problemas socioeconômicos e socioambientais que se tornaram preocupações cada vez mais presentes para o planejamento e para a gestão urbana. É nesse sentido que temas relacionados ao desenvolvimento sustentável vêm sendo debatidos por pesquisadores nos níveis técnicos e científicos. Dentre os temas, destacamos a preocupação com o meio urbano e a sua sustentabilidade. Nesta pesquisa, buscamos entender a praça enquanto um elemento estruturador do espaço urbano por atender a várias funções, dentre elas: social, estética, ecológica, paisagística, climática, psicológica e recreativa.

Dessa forma, a praça pública é utilizada pela população como espaço de lazer, de descanso, de circulação de pessoas, de embelezamento ou apenas desfruta-se de sua paisagem por proporcionar um contato mais próximo com a natureza no meio urbano. Dada a importância da praça para a população citadina, a presente pesquisa tem como objetivo/intenção caracterizar e analisar a Praça São José e a Praça Getúlio Vargas na cidade de Campo Mourão (PR), destacando-se os aspectos paisagísticos e as infraestruturas existentes. Também se pretende propor medidas que auxiliem no planejamento e gerenciamento destes logradouros.

\section{A PRAÇA ENQUANTO ESPAÇO PÚBLICO: BREVES REFLEXÕES TEÓRICAS}

A praça é um dos principais elementos que compõem uma cidade. Na história da humanidade, encontramos praças desde tempos mais antigos. A Ágora, na Grécia antiga, e o Fórum romano eram os espaços públicos de uso coletivo mais importantes na cidade, servindo como ponto de encontro, comércio e circulação de 


\section{Revista Nacional de}

Gerenciamento de Cidades

pessoas. Na Idade Média, as praças assumem funções específicas: praça da igreja, praça de mercado, praça de entrada da cidade, praça do centro da cidade, entre outras. No Renascimento, além dos valores funcionais, elas ganham valores estéticos e passam a ornamentar a cidade. Segundo De Angelis et al. (2005), é nesse período histórico que a praça se converte em um dos principais elementos urbanísticos para a transformação e embelezamento das cidades.

No Brasil, as praças coloniais surgiram a partir das igrejas, como observamos em Marx (1980, p. 222): "logradouro público por excelência, a praça deve sua existência, sobretudo, aos adros das nossas igrejas". A partir da igreja e da praça surgia a cidade com os principais prédios públicos e melhores moradias, sendo, portanto, os espaços mais nobres da cidade. Nas palavras de Robba e Macedo (2002, p. 22), "era ali que a população colonial manifestava sua territorialidade, os fiéis demonstravam sua fé, os poderosos, seus poderes, e os pobres, sua pobreza". Apesar de terem sido, por muito tempo, símbolo do poder religioso, as praças brasileiras também representavam as funções cívicas e militares.

Com o aumento da população e o crescimento desordenado das cidades brasileiras, os espaços livres passaram a ser cada vez mais valorizados tanto para recreação como para embelezamento da cidade. Tal fato altera a função das praças brasileiras e marca o surgimento das praças ajardinadas na história dos espaços livres urbanos no país.

Para estudar as praças brasileiras, precisamos considerar o desenvolvimento do paisagismo no país. Segundo De Angelis (2000), o paisagismo brasileiro se define no século XIX a partir da consolidação de uma rede de cidades, situadas principalmente ao longo do litoral e sob forte influência urbanística europeia (francesa e inglesa), que contribuiu para a criação de espaços públicos (parques, praças e boulevards).

Macedo (1998, p.15), por meio do Projeto Quapa, destaca o paisagismo brasileiro em três períodos distintos: o ecletismo, o moderno e o contemporâneo: 
a) Ecletismo: Recebeu forte influência européia. Marcado pelo surgimento dos primeiros parques públicos, praças ajardinadas, jardins dos barões do café.

b) Moderno: Marcado pelo uso de vegetação nativa e rompimento com escola clássica. Destaque para os trabalhos de Roberto Burle Marx em Recife e Rio de Janeiro.

c) Contemporâneo: Recebeu influência paisagística japonesa, americana e francesa utilizando estruturas construídas e vegetação. Desenvolveu-se a partir dos anos 1980 e 1990.

A incorporação da vegetação no espaço público brasileiro mostra a necessidade do contato do homem urbano com a natureza, fato marcado pelo surgimento de hábitos de jardinagens, pela abertura dos jardins botânicos para a população e pela arborização das ruas e praças públicas.

Em síntese, os imensos espaços abertos e sem vegetação, que serviam apenas como local de encontro, começam a ser planejados para atender às novas funções que surgem nas cidades brasileiras. A inserção de arborização, inclusive a nativa que antes era desvalorizada, colabora para que o espaço urbano seja pensado tanto em nível estético como em nível funcional.

Hoje, essa valorização passa a constituir em um dos indicadores de qualidade dos espaços livres públicos, pois além de servir como um fator de embelezamento da cidade, permite uma ruptura na paisagem constituída por edificações, proporcionando tanto espaços de passagem, embelezamento e ordenamento urbano quanto espaço de sociabilidade da população. Porém, apesar do empenho das administrações municipais em equipar e manter as praças públicas brasileiras, percebe-se um abandono desses espaços por parte da população, principalmente nos grandes centros, que apresentam outros atrativos de consumo e lazer como shoppings e televisão.

Vários pesquisadores, dentre eles Marx (1980), Ferrara (1993), Segawa (1996), Robba e Macedo (2002), Sun Alex (2008), Serpa (2011) têm discutido em seus trabalhos a importância das praças públicas na sociedade brasileira. 
Para Robba e Macedo (2002), estudos sobre praça devem considerar seu uso e sua acessibilidade. No primeiro caso, por ser espaço público urbano destinado ao lazer e ao convívio da população, e acessibilidade por ser espaço livre de veículos e acessível ao cidadão.

Outro autor que discute a questão da acessibilidade é Sun Alex (2008), para o qual "a praça não é apenas um espaço físico aberto, mas também um centro social integrado ao tecido urbano. Sua importância refere-se a seu valor histórico, bem como a sua participação contínua na vida da cidade" (2008, p. 23). Destaca que a acessibilidade é um dos fatores fundamentais para o uso e apropriação do espaço público. $O$ acesso a esse espaço pode ser físico (com barreiras físicas que impeçam o acesso), visual (ameaça visual de que o lugar não é seguro) e simbólico ou social (sinais que sugerem quem não é bem vindo ao local); eles podem ser combinados tornando o local mais ou menos convidativo ao uso (2008, p. 25).

Como dito anteriormente, as praças são elementos de grande importância para a população à medida que atendem às várias funções: estética (embelezamento), ambiental (qualidade do ambiente), social (convivência entre pessoas de faixa etária diversa) e simbólica (lazer, descanso). A questão da acessibilidade, portanto, é primordial para garantir o uso e a permanência das pessoas nos espaços públicos. Sun Alex (2008) alerta que:

O desuso das praças acarreta a perda de oportunidades de sociabilização e de fortalecimento da cidadania, contribuindo para o aumento da dependência de espaços privados para a prática da vida pública e, consequentemente, das desigualdades sociais e da exclusão. Garantir o acesso público e o uso coletivo - condições essenciais para promover a vida pública nas praças - é um desafio e uma responsabilidade para a cidade e para o paisagismo. (ALEX, 2008, p.279)

O espaço público é compreendido por Serpa (2011, p. 9) como espaço da ação política, ele o analisa enquanto mercadoria para consumo de poucos segundo a lógica do sistema capitalista. Para tanto, aborda os conceitos de: cidadania, política e acessibilidade. A acessibilidade física (sem barreiras que impeçam o 


\section{Revista Nacional de}

Gerenciamento de Cidades

acesso) e também a acessibilidade simbólica (à medida que a apropriação espacial seleciona ou limita o acesso ao espaço público).

Para Serpa (2011), as transformações urbanas têm sofrido influência do consumo e do lazer da classe média, multiplicando, assim, a valorização do solo. Aponta que há uma tendência em se investir em espaços públicos "visíveis", aqueles com maior destaque na cidade.

\section{METODOLOGIA}

Para a realização desta pesquisa, adotamos os seguintes procedimentos metodológicos: pesquisa bibliográfica sobre praças públicas, áreas verdes urbanas e espaço público; trabalho de campo para levantamento das estruturas e mobiliários presentes nas Praças São José e Getúlio Vargas da cidade de Campo Mourão e registro fotográfico dessas estruturas.

Para avaliar de forma qualitativa e quantitativa as estruturas e mobiliários, utilizaremos a metodologia desenvolvida por De Angelis (2000), que estabelece parâmetros fixos de avaliação das estruturas existentes nas praças: bancos, iluminação, sanitários, lixeiras entre outras. Com o estabelecimento de parâmetros fixos, buscamos evitar que o mesmo equipamento seja avaliado de forma diferente.

O registro fotográfico permitirá apresentar em forma de mosaico a qualidade das estruturas e mobiliários presentes nas Praças São José e Getúlio Vargas.

\section{ANÁLISE DOS RESULTADOS}

A presente pesquisa teve como recorte espacial as Praças São José e Getúlio Vargas (Figura 1) do município de Campo Mourão, que está localizado na Mesorregião Centro Ocidental Paranaense. Segundo o IBGE (2014), possui população total de 87.194 habitantes, sendo 4.518 habitantes residentes na área rural e 82.676 na área urbana. Conforme o Instituto Paranaense de 

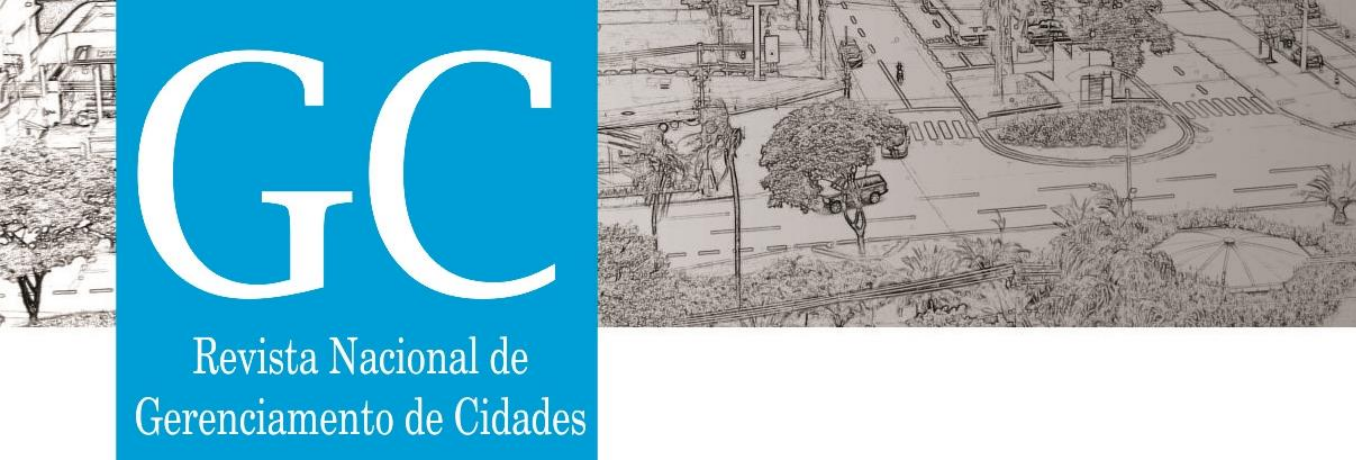

Desenvolvimento Econômico e Social (IPARDES, 2015), esse município possui uma área de 763,637 km², está a 447,18 km distante da capital do estado e o Índice de Desenvolvimento Humano (IDH), em 2010, era de 0,757, ligeiramente acima do índice do estado que é de 0,749 .

As praças São José e Getúlio Vargas estão localizadas na área central da cidade de Campo Mourão. Na década de 1940, compunham um único espaço no entorno da igreja São José, destinado às comemorações religiosas.

Figura 1: Praças Centrais de Campo Mourão.

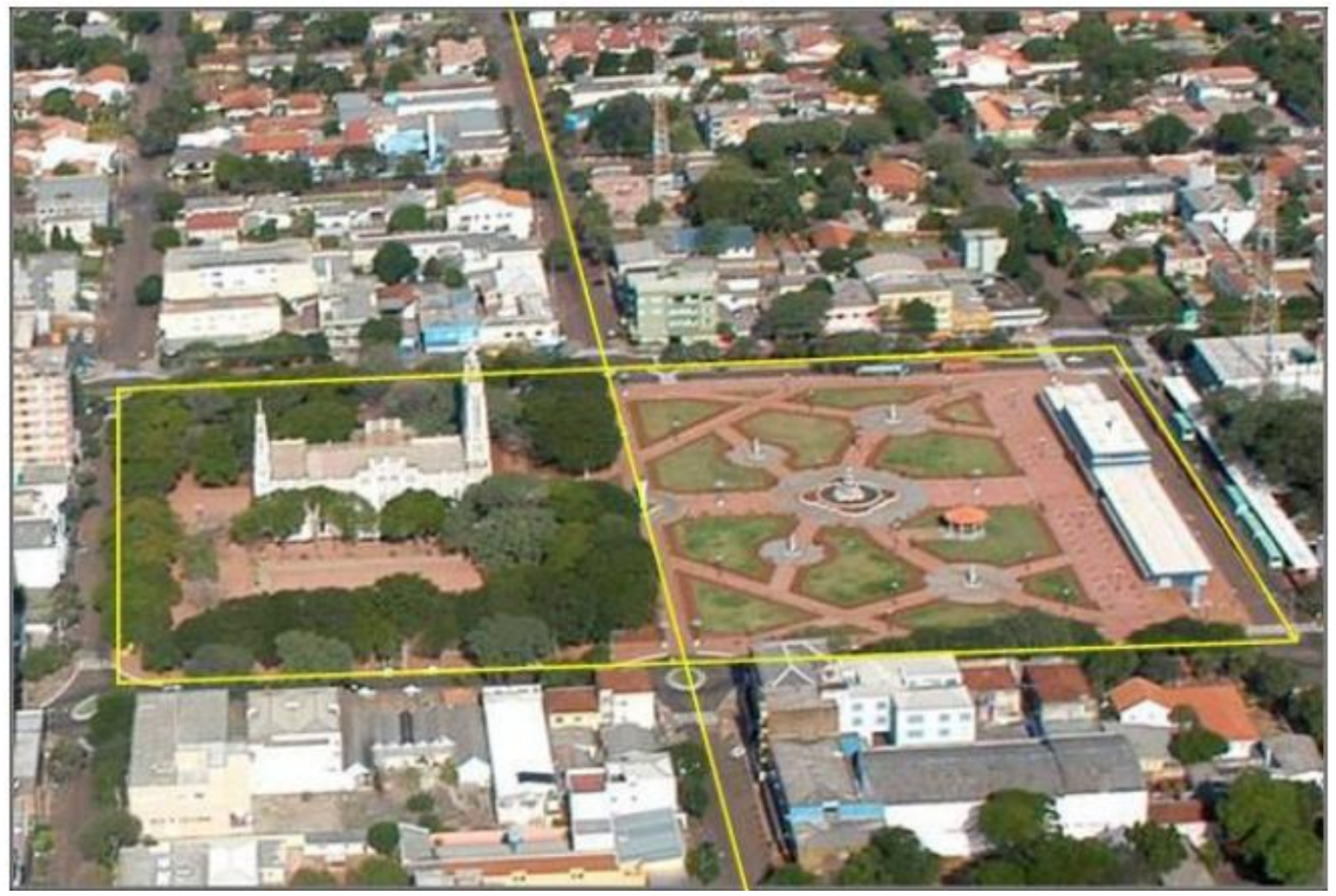

Fonte: Museu Municipal Deolindo Mendes Pereira, 2015.

Com o mapeamento e demarcação dos primeiros quarteirões para formação do núcleo urbano de Campo Mourão, a praça foi fragmentada em dois espaços: um deles continuou destinado às atividades religiosas e o outro ao lazer da população. 


\section{Revista Nacional de}

Gerenciamento de Cidades

A Praça Getúlio Vargas foi oficializada no final da década de 1950, e a Praça São José na segunda metade da década de 1960.

$\mathrm{Na}$ década de 1980, foi construído, no lugar da igreja São José, a nova Catedral da cidade. Nessa época, o poder público municipal fechou a Rua Brasil e construiu um calçadão entre as duas praças, passando a falsa impressão da existência de apenas uma praça.

A partir da década de 1990, outros grupos passaram a frequentar esses espaços, como andarilhos, prostitutas, etc. Na tentativa de resgatar tais logradouros, em 2004 o poder público municipal revitalizou-os e reabriu a Rua Brasil; porém, devido à proximidade e à padronização dos mobiliários, a impressão de uma única praça permanece.

A pesquisa in loco proporcionou apresentar uma análise detalhada de todos os equipamentos existentes nas duas praças. Logo, por serem semelhantes, apresentaremos uma análise integrada das principais estruturas e mobiliários presentes nestas praças, conforme apresentamos nos mosaicos das Figuras 2 e 3 .

Quanto aos caminhos, são pavimentados por bloquetes que facilitam o acesso e a circulação de transeuntes em diferentes áreas da praça, inclusive em dias de chuva. A pavimentação encontra-se em ótimo estado de conservação, o traçado é adequado do ponto de vista funcional e estético e tem uma largura adequada para a circulação.

Outro mobiliário de grande relevância são os bancos, pois permitem que as pessoas permaneçam na praça para descansar, contemplar a natureza, ler ou encontrar com amigos. Os bancos possuem os pés ornamentados, de ferro, com encosto e assento em madeira, e estão bem conservados e distribuídos por toda a praça, proporcionando o uso e a permanência das pessoas.

Localizamos lixeiras de plástico sobre estrutura de metal em bom estado de conservação; porém, insuficientes para atender de forma satisfatória. Observamos apenas um ponto de água em cada praça, utilizados para limpeza e irrigação das plantas, não sendo possível saciar a sede dos usuários. 


\section{Revista Nacional de}

Gerenciamento de Cidades

Na Praça São José há um palco e um amplo espaço de onde acontecem eventos, religiosos ou não. Na foto, podemos observar estruturas metálicas de um evento dos comerciantes locais que havia ocorrido no final de semana. A Catedral utiliza uma parte do seu entorno como estacionamento particular, atendendo a falta de estacionamento do centro da cidade.

O destaque da Praça Getúlio Vargas é o chafariz que atrai a atenção de crianças e adultos por sua beleza; à noite ele possui iluminação própria. Nessa praça, encontramos um prédio institucional, a Biblioteca Pública Municipal, que atende toda a população. Encontramos uma placa de identificação com referência às duas praças, mas em péssimo estado de conservação, não sendo possível identificar o seu conteúdo. Há um coreto que está fechado atualmente e um ponto de táxi.

As Praças São José e Getúlio Vargas formam um espaço público fundamental para o desenvolvimento da cidadania, pois proporcionam a integração de usuários de diferentes níveis sociais e econômicos. Nota-se que há investimento por parte do poder público e religioso para que as praças tenham a configuração atual e possa atender às funções delas esperadas.

No entorno das praças encontramos o centro comercial da cidade com lojas de vestuário, lojas de produtos agrícolas, sapatarias, relojoarias, livrarias, farmácias, hotéis, restaurantes, agência dos correios, Prefeitura Municipal de Campo Mourão, Câmara Municipal de Campo Mourão, Colégio Vicentino Santa Cruz entre outros.

\section{CONSIDERAÇÕES FINAIS}

Com a análise dos resultados obtidos no levantamento dos aspectos quantitativos e qualitativos dos equipamentos e estruturas existentes nas Praças São José e Getúlio Vargas, foi possível concluir que ambas desempenham as funções estética, ambiental e social. A mais evidente é a social, pois as estruturas 


\section{Revista Nacional de}

Gerenciamento de Cidades

presentes possibilitam o convívio e a integração de pessoas de níveis sociais, culturais, econômicos e idades diferentes.

O poder público municipal e as entidades religiosas, enquanto gestores desses espaços públicos, estão atuando na manutenção e conservação da praça. No entanto, com intuito de contribuir com as futuras implementações ou reformas, deixamos algumas sugestões pensando no conforto dos usuários das praças. A instalação de parque infantil seria uma opção de lazer para a população, pois não encontramos atividades de lazer gratuitas na cidade. Para que seja, efetivamente, um elemento integrador, necessita estar em boa qualidade de uso e adequado a capacidade psicomotora dos usuários, que tenha cores e modelos variados e em quantidade suficiente para atender o público. A instalação de um módulo policial seria uma opção para aumentar a segurança dos usuários. A instalação de alguns pontos de água (bebedouros) contribuiria com o conforto dos usuários.

\section{REFERÊNCIAS BIBLIOGRÁFICAS}

ALEX, Sun. Projeto da praça: convívio e exclusão no espaço público. 2. Ed. São Paulo: Editora Senac, 2008.

DE ANGELIS, Bruno Luís Domingos de. A Praça no Contexto das Cidades: o caso de MaringáPR. Tese de (Doutorado em Geografia). Faculdade de Filosofia, Letras e Ciências Humanas Universidade de São Paulo. São Paulo, 2000.

FERRARA, Lucrecia D’Alesio. As Máscaras da Cidade. In: Olhar Periférico: informação, linguagem, percepção ambiental. São Paulo: Edusp/Fapesp. 1993.

IBGE. Censos Demográficos. Rio de Janeiro, IBGE, 2014.

IPARDES, Instituto Paranaense de Desenvolvimento Econômico e Social. Caderno estatístico município de Campo Mourão. Disponível em: <http://www.ipardes.gov.br/>. Acesso em: 16 set. 2015.

MACEDO, Silvio Soares. (Coord.) Introdução a um Quadro Paisagístico no Brasil. Projeto Quapá, Faculdade de Arquitetura e Urbanismo - Universidade de São Paulo, 1998.

MARX, Murilo. Cidade Brasileira. Melhoramentos. Editora da Universidade de São Paulo, 1980.

ROBBA, F; MACEDO, S.S. Praças Brasileiras: public squares in Brazil. São Paulo. Edusp: Impressa oficial do Estado. 2002. 
